American J. of Engineering and Applied Sciences 3 (2): 350-354, 2010

ISSN 1941-7020

(C) 2010 Science Publications

\title{
Investigation of the Dimensions Design Components for the Rectangular Indirect Resistance Electrical Furnaces
}

\author{
Salah K. Jawad \\ Department of Production and Metallurgy Engineering, \\ University of Technology, Baghdad, Iraq
}

\begin{abstract}
Problem statement: The objective of this study was to study the Indirect Resistance Electrical Furnaces (IREF) based on analytical and experimental analyses. The analytical analysis focused on a constant set of equations representing the internal and external flow of heat energy in the furnace, which demonstrated, relatively with the surface area of walls, heat transferring inside the furnace chamber to get a creation mathematical model including the joining between the temperature required design components (furnace walls, thickness and electrical power supply). Approach: The experimental analysis has divided in to tow parts; first part based on process number of practice experiments with three prototypes have manufactured in certain engineering dimensions that changed in three different volumes of furnace, which are considered, i.e., chamber volume of furnace is the design dimensions component. Results: The second part of analytical analysis based on use the Simulink program (MATLAB 7.4) compared with experimental results of the manufactured furnaces samples, which showed the direct effect of the design dimensions components on the performance specifications of furnace that involve the required temperature response, temperature stability and the deviation in the setting value of temperature. Conclusion: Although information relating to the design and fabrication of an indirect resistance electrical furnaces of such prototypes as that fabricated through this research was not readily available in the literature.
\end{abstract}

Key words: Indirect resistance, electrical furnaces, chamber volume

\section{INTRODUCTION}

There are many classifications of indirect resistance furnaces, but the class according to the position style of heat elements is considered widespread. The hidden thermal elements are hidden in the walls to make an indirect heating treatment like shown in the Fig. 1; the hidden thermal elements resistance furnace has a tubular heating element with a vertically oriented longitudinal axis. The heating element is connected to supply terminals by which heating current is introduced at power supply points into the heating element (Krivandin and Markov, 1980).

Furnace is a structure for heat exchange between a surrounding medium and the charged metals (materials) in which a regular monitoring of temperature at required intervals of time is incorporated. Furnaces are of various sizes, i.e., small, medium and large, depending on the quantity of heat and efficiency required (Ziyad and Mohammed, 2007). Design of metallurgical furnaces involves considerations of the mode of operation, its heating mechanism, heat transfer within the furnace, waste utilization, materials and elements of furnaces, capacity and efficiency. In addition, the energy utilization in a furnace is paramount in the furnace design analysis. By their operations, all metallurgical furnaces were classified into melting and heating furnaces (Oyawale and Olawale, 2007).

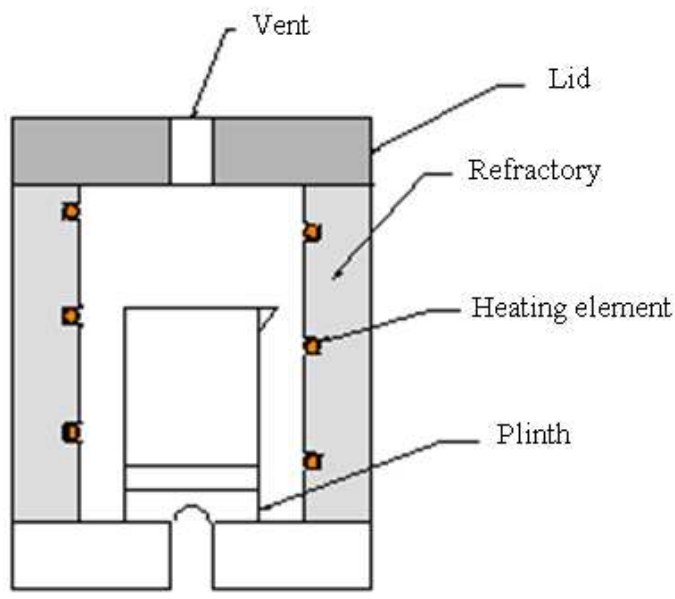

Electric furnace

Fig. 1: Indirect resistance electrical furnace (embedded heating elements) (Chook et al., 2005) 
The energy utilization in an electric furnace is the basis for its design consideration to achieve effective performance. It also helps and guides in the determination of the scale of performance for both the metallurgical and economic considerations. The analysis is used primarily to determine the basic required design parameters of the heater materials for electrical furnaces (rectangular and cylindrical), to predict the furnace performance, suitability and its financial implications, the improvements in this type of furnaces cannot be achieved without detailed investigation of the furnace components characteristics. This study is aimed to investigate the design components that given suitable specification of performance and developing the general theoretical and ideas on the relationship between operating temperature and the furnace parameters as its design dimension (Ram and Patel, 1998).

\section{MATERIALS AND METHODS}

Analytical analysis: two-bar-description is developed to model the thermal behavior of indirect resistance electrical furnace as shown in Fig. 2 that represented the two dimensional section of furnace chamber. The generation of thermal energy by electrical resistance of the heating elements involves the transfer of quantities of the energy that leads to reach the temperatures for the furnace chamber and then to its walls, the heat transfer may occur through conduction, convection or radiation and the heat transfer system according on the operation temperature range inside the furnace (White et al., 2009), but in this study it has assume conventional heat transfer because of medium temperature range required lower than $800^{\circ} \mathrm{C}$ approximately.

Theoretical aspects: The set of equations have applied on operation system of (IREF) heat generation furnace include the first law of thermodynamics Eq. 1, the two terms $\mathrm{Q}_{\text {in }}, \mathrm{Q}_{\text {out }}$ represent flow of internal and external thermal energy respectively which are cleared proportionally with the surface area as a result of convection heat transfer Eq. 2. The term $\mathrm{Q}_{\mathrm{gen}}$ is related with conversion of electrical power to heat energy Eq. 3 and the term $Q_{\text {acc }}$ is storage accumulated energy in the medium that is remaining as required quantity heat energy in the furnace Eq. 4 (Incropera Frank, 2002):

$\mathrm{Q}_{\mathrm{in}}+\mathrm{Q}_{\mathrm{gen}}-\mathrm{Q}_{\mathrm{out}}=\mathrm{Q}_{\mathrm{acc}}$

$\mathrm{Q}=\mathrm{hA}\left(\mathrm{t}_{\mathrm{w}}-\mathrm{t}_{\infty}\right)$
$\mathrm{P}=\mathrm{I}^{2} \mathrm{R}$

$\mathrm{Q}_{\mathrm{acc}}=\rho \mathrm{VC} \frac{\mathrm{dT}}{\mathrm{dt}}$

Mathematical modeling: The operation of an electric resistance heating furnace indicates that heat energy is lost both as a heat in the furnace space (chamber) and as heat energy in another component such the furnace walls. For this purpose, the heat balance should be complemented with applying heat balance on the both parts of furnace space and walls (Zghair, 2006).

- The applying of heat balance with furnace space by using Eq. 1 will give the following:

$$
P-A_{c} h_{c}\left(T_{c}-T_{w}\right)=\rho_{c} V_{c} C_{c} \frac{d T_{c}}{d t}
$$

Equation 5 represents unsteady state, the assuming of steady state it will give:

$$
\mathrm{P}_{\mathrm{s}}-\mathrm{A}_{\mathrm{c}} \mathrm{h}_{\mathrm{c}}\left(\mathrm{T}_{\mathrm{cs}}-\mathrm{T}_{\mathrm{ws}}\right)=\rho_{\mathrm{c}} \mathrm{V}_{\mathrm{c}} \mathrm{C}_{\mathrm{c}} \frac{\mathrm{dT} \mathrm{T}_{\mathrm{cs}}}{\mathrm{dt}}=0
$$
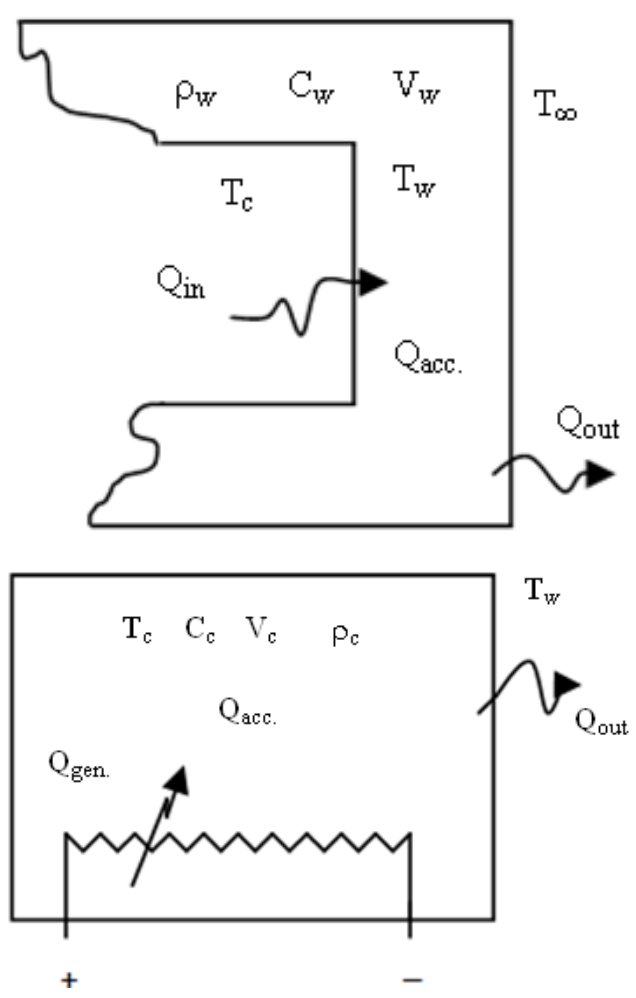

Fig. 2: Cross-sectional of furnace chamber (Zghair, 2006) 
By subtracting Eq. 6 from Eq. 5 and putting of the upper dash of symbols that indicate to subtract steady state from unsteady state. The term $\frac{\mathrm{dT}_{\mathrm{cs}}}{\mathrm{dt}}=0$; because of no change in temperature at steady state:

$\mathrm{Q}^{\prime}-\mathrm{A}_{\mathrm{c}} \mathrm{h}_{\mathrm{c}}\left(\mathrm{T}_{\mathrm{c}}^{\prime}-\mathrm{T}_{\mathrm{w}}^{\prime}\right)=\frac{\rho_{\mathrm{c}} \mathrm{V}_{\mathrm{c}} \mathrm{C}_{\mathrm{c}} \mathrm{d}^{\prime} \mathrm{T}_{\mathrm{c}}}{\mathrm{dt}}$

By dividing of Eq. 7 on $A_{c} h_{c}$ and taking of Laplace transformation, it will give:

$\mathrm{T}_{\mathrm{c}(\mathrm{S})}^{\prime}=\frac{\mathrm{Q}_{(\mathrm{S})}^{\prime \prime}}{\tau_{1} \mathrm{~S}+1}+\frac{\mathrm{T}_{\mathrm{w}(\mathrm{S})}^{\prime}}{\tau_{1} \mathrm{~S}+1}$

- Also applying of heat balance with furnace walls by using same procedure, it will give the following:

$\mathrm{T}_{\mathrm{w}(\mathrm{s})}^{\prime}=\frac{\mathrm{K}_{1}}{\left[\left(\tau_{2} \mathrm{~S}+\left(\mathrm{K}_{1}+1\right)\right)\right]} \mathrm{T}_{\mathrm{c}(\mathrm{S})}^{\prime}+\frac{1}{\left[\left(\tau_{2} \mathrm{~S}+\left(\mathrm{K}_{1}+1\right)\right)\right]} \mathrm{T}_{\infty(\mathrm{S})}^{\prime}$

Where:

$$
\begin{aligned}
& \frac{\rho_{\mathrm{w}} \mathrm{V}_{\mathrm{w}} \mathrm{C}_{\mathrm{w}}}{\mathrm{A}_{\mathrm{w}} \mathrm{h}_{\mathrm{w}}}=\tau_{2} \\
& \frac{\rho_{\mathrm{c}} \mathrm{V}_{\mathrm{c}} \mathrm{C}_{\mathrm{c}}}{\mathrm{A}_{\mathrm{c}} \mathrm{h}_{\mathrm{c}}}=\tau_{1} \\
& \frac{\mathrm{A}_{\mathrm{c}} \mathrm{h}_{\mathrm{c}}}{\mathrm{A}_{\mathrm{w}} \mathrm{h}_{\mathrm{w}}}=\mathrm{K}_{1}
\end{aligned}
$$

Then sub. Eq. 9 in Eq. 8:

$$
\begin{aligned}
\mathrm{T}_{\alpha \mathrm{S})}^{\prime}= & \frac{\mathrm{K}(\tau \mathrm{S}+1)}{\left[\tau_{1} \tau_{2} \mathrm{~S}^{2}+\left(\tau_{1}+\tau_{1} \mathrm{~K}_{1}+\tau_{2}\right) \mathrm{S}+1\right]} \mathrm{Q}_{(\mathrm{S})}^{\prime \prime}+ \\
& \frac{1}{\left(\tau_{1} \tau_{2} \mathrm{~S}^{2}+\left(\tau_{1}+\tau_{1} \mathrm{~K}_{1}+\tau_{2}\right) \mathrm{S}+1\right)} \mathrm{T}_{\infty(\mathrm{S})}^{\prime}
\end{aligned}
$$

where, $\left(\mathrm{K}_{1}+1\right)=\mathrm{K}$ and $\frac{\tau_{2}}{\mathrm{~K}}=\tau$.

\section{RESULTS}

To validate the mathematical model that has developed in this study Eq. 10, which included the design components of furnace and to investigate the effects of dimensions design of the chamber on the furnace performance corresponding on TemperatureTime curve as a criteria to analysis, the experimental procedure was as the following:

- The MATLAB 7.4 program has used through building certain simulink to simulate Eq. 10

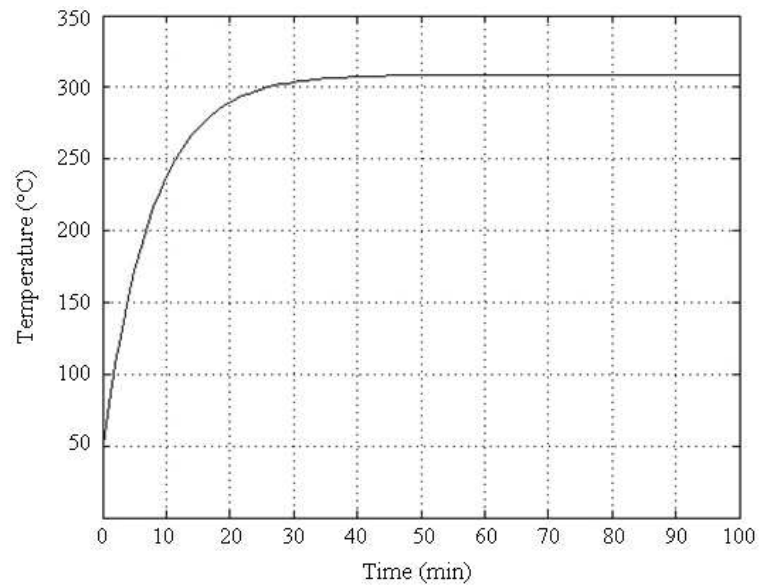

(a)

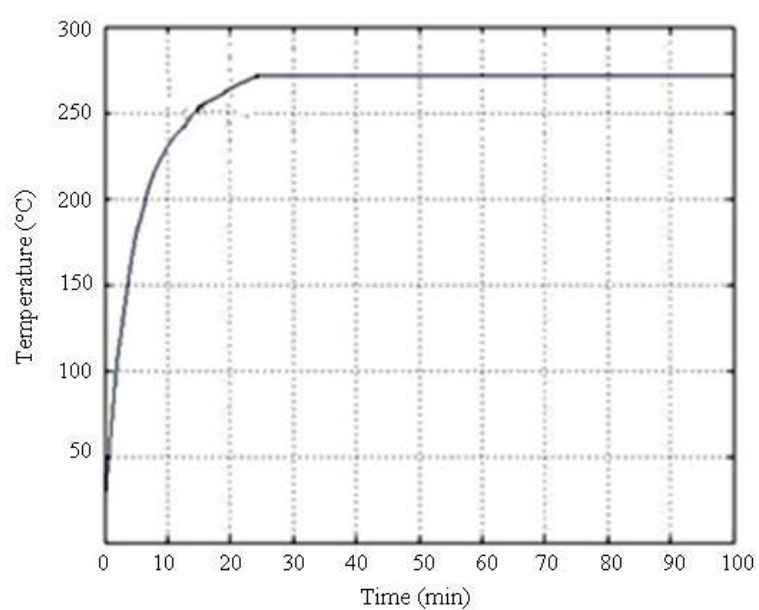

(b)

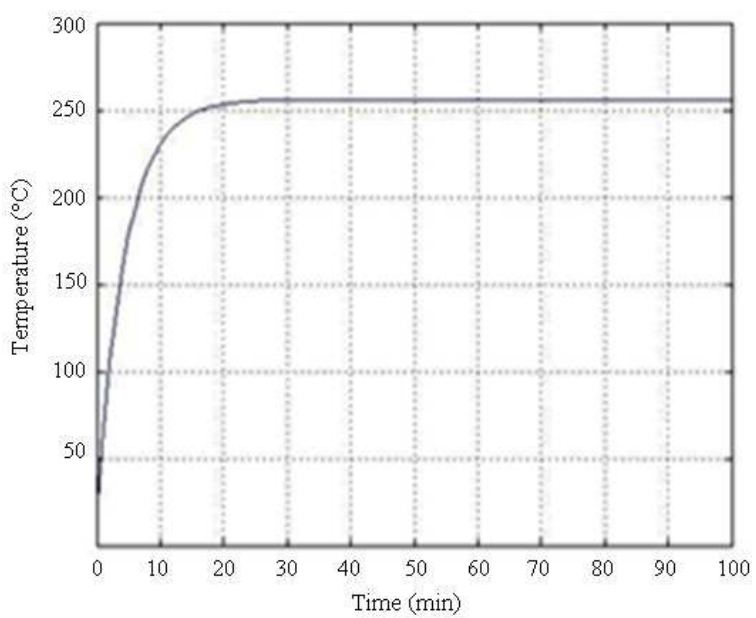

(c)

Fig. 3: The relation between temperature and the time under different No. of volume (theatrical). (a) $\mathrm{V}_{1}$; (b) $\mathrm{V}_{2}$; (c) $\mathrm{V}_{3}$ 


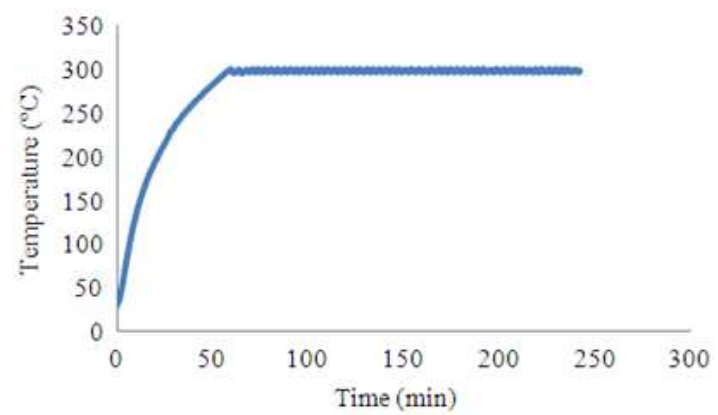

(a)

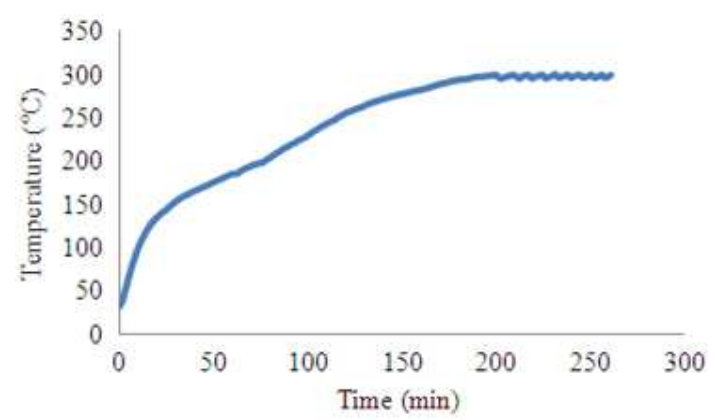

(b)

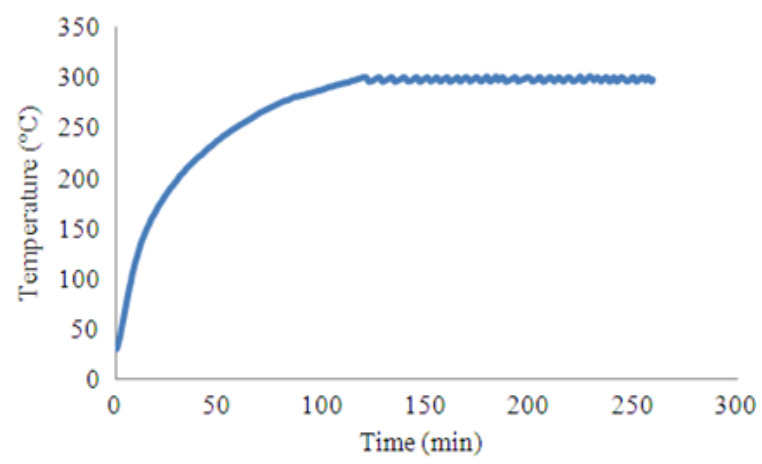

(c)

Fig. 4: The relation between temperature and the time under different No. of volume (experimental). (a) $\mathrm{V}_{1}$; (b) $\mathrm{V}_{2}$; (c) $\mathrm{V}_{3}$

- The test of the equation by drawing the thermal behavior with changeable entries of chamber volume was accomplished in three values o $\mathrm{f}$ dimensions, $\left(\mathrm{V}_{1}=30 \times 30 \times 40 \mathrm{~cm}^{3}, \mathrm{~V}_{2}=40 \times 40 \times 50\right.$ $\left.\mathrm{cm}^{3}, \mathrm{~V}_{3}=50 \times 50 \times 60 \mathrm{~cm}^{3}\right)$.

- Running the program with variable volumes as demonstrated above in point No. 2 to obtain theoretical results as shown in the Fig. 3

- Three prototypes of furnaces have fabricated according to virtual volumes and the mathematical model entries, which have same thickness of wall is $(5 \mathrm{~cm})$
- Doing the operation tests of prototypes to monitoring the performance with the following steps:

- Repairing and fixing the operation conditions (power $=1300 \mathrm{~W}$, setting value of temperature $=300^{\circ} \mathrm{C}$ )

- Recording the elevation of the temperature value every $1 \mathrm{~min}$

- Repeating the operating test of every prototype

- Plotting the experimental results in the temperature-time-curve as shown in Fig. 4

\section{DISCUSSION}

Bases on the theoretical and experimental results, the thermal behavior of theoretical diagrams Fig. 3a-c and the experimental diagrams Fig. 4a-c have approved the validity of the mathematical model Eq. 10 and its assumptions through monitoring the symmetrical in the experimental curves with theoretical except the little deviation between it that refer to operating and fabricating conditions of prototypes, in general, that is introduce to the successful of target of this study which represented of investigation the effect of the design dimensions of chamber, the design dimensions which are the volume and surface areas $\mathrm{V}_{\mathrm{c}}, \mathrm{V}_{\mathrm{w}}, \mathrm{A}_{\mathrm{c}}$ and $\mathrm{A}_{\mathrm{w}}$ as preview in Eq. 11-14 below that entry in the model building and prototype changing were demonstrated the direct effect on the performance specifications of furnace which are required temperature $T_{c}$, the speed of response of $T_{c}$ and the deviation of $T_{c}$ :

$$
\begin{aligned}
& \mathrm{V}_{\mathrm{c}}=\ell \mathrm{wh} \\
& \mathrm{V}_{\mathrm{w}}=(\ell+2 \mathrm{~T})(\mathrm{w}+2 \mathrm{~T})(\mathrm{h}+2 \mathrm{~T})-(\ell \mathrm{wh})
\end{aligned}
$$

$\mathrm{A}_{\mathrm{c}}=2(\mathrm{~h} \ell+\ell \mathrm{w}+\mathrm{wh})$

$$
A_{w}=2\left[\begin{array}{l}
(2 T+\ell)(2 T+h)+(2 T+\ell)(2 T+w)+ \\
(2 T+w)(2 T+h)
\end{array}\right]
$$

\section{CONCLUSION}

Such as these analyses become more important and challenging for investigators because electrical, thermal and economical problems are involved. Thermal problems are the most interesting and important ones, because it is difficult to solve owing primarily to the variation of parameters with temperature, because it obtained results utilized to form the basic investigation for relationships between the required temperature and 
the dimensions design components. Although information relating to the design and fabrication of an indirect resistance electrical furnaces of such prototypes as that fabricated through this research was not readily available in the literature.

\section{REFEZENCES}

Chook, K.C., A.H. Tan, W.O. Siew and W.H. Tan, 2005. Static nonlinear compensator design for bilinear systems with an application on a furnace. Proceedings of the IEEE Instrumentation and Measurement Technology Conference, May 16-19, IEEE Xplore Press, Ottawa, Ont., pp: 1272-1277. DOI: 10.1109/IMTC.2005.1604352

Incropera Frank, P., 2002. Introduction to Heat Transfer. John Wiley and Sons, Inc., ISBN: 13: 978-0471386490, pp: 912.

Krivandin, V. and B. Markov, 1980. Metallurgical Furnaces. MIR Publishers, ISBN: 0-08-017786-7.

Oyawale, F.A. and D.O. Olawale, 2007. Design and prototype development of a mini-electric arc furnace. Pacif. J. Sci. Technol., 8: 1-5. http://www.akamaiuniversity.us/PJST8_1_12.pdf
Ram, B. and G. Patel, 1998. Modeling furnace operations using simulation and heuristics. Proceedings of the Simulation Conference, Dec. 13-16, IEEE Xplore Press, USA., pp: 957-963. DOI: 10.1109/WSC.1998.745799

White, R.S., T.J. Dionise and J.A. Baron, 2009. Design, analysis and operation of the electrical distribution system for a modern electric arc furnace and ladle melt furnace. Proceeding of the Industry Applications Society Annual Meeting, Oct. 4-8, IEEE Xplore Press, Houston, TX., pp: 1-7. DOI: 10.1109/IAS.2009.5324848

Zghair, H.R., 2006. A study to determine the government parameters of temperature in indirect electrical resistance furnace. MSc Thesis, University of Technology.

Ziyad, N.M. and F.D. Mohammed, 2007. A graphical design of an input-shaping controller for quay side container cranes with large hoisting: Theory and experimental. Jordan J. Mech. Ind. Eng., 1: 57-67. 